\title{
40. PROVENANCE CHANGES OF FINE QUARTZ SANDS IN GLACIAL AND INTERGLACIAL INTERVALS OF THE FENI AND GARDAR DRIFTS, NORTH ATLANTIC: FOURIER SHAPE ANALYSIS ${ }^{1}$
}

\author{
Margaret R. Eggers, and Robert Ehrlich, Department of Geology, University of South Carolina²
}

\begin{abstract}
Using a combination of Fourier shape analysis and scanning electron microscopy, very fine quartz sand grains from sediments of the Feni and Gardar drifts (Holes 610A and 611A) were analyzed to obtain provenance information. Three grain populations were defined: (1) smooth: grains covered with fine-grained silica plastering, interpreted as weathered from continental bedrock; (2) intermediate: angular, freshly fractured grains, probably transported by glaciers and icerafting; and (3) irregular: grains covered with irregular, platy silica overgrowths, likely the products of submarine erosion of fine-grained marine sediments. Examination of the proportions of each grain type in samples from intervals interpreted to be glacial (dark, calcareous muds) and interglacial (light-colored calcareous oozes) showed that there are changes in provenance across the boundaries between these intervals. Proportions of each grain type vary widely within glacial intervals, but remain relatively invariant in interglacials. This suggests that factors affecting provenance, such as the amount of sea ice, water depth on the continental shelf, and strength and direction of bottom currents, are more variable during glacial periods. Presence of the irregular grain type indicates that erosion and redeposition of marine sediments is a major source of sediment in sediment drifts in the deep sea.
\end{abstract}

\section{INTRODUCTION}

The top 130 to $150 \mathrm{~m}$ of the Feni and Gardar drifts (Sites 610 and 611) consists of interbedded dark and light sediment layers. They are from less than one meter to several meters thick and are thought to have been deposited during glacial (dark) and interglacial (light) intervals. If these sediments do represent climatic fluctuations, then one would expect to find evidence of provenance variations in the detrital component, corresponding to changes in available source material and bottom-current trajectories-for example, as related to Norwegian Sea overflow or Pleistocene equivalents. To detect such changes in provenance, quartz from the very fine sand fraction of several of these intervals from both sites was examined, using a combination of Fourier shape analysis and the scanning electron microscope.

\section{METHODS AND PROCEDURES}

All samples in this study were soaked in a soap solution to deflocculate clays, boiled in hydrochloric acid to remove carbonate material, and then washed, dried, and sieved. The results described here were obtained by analysis of quartz particles from the very fine sand fraction $(63-90 \mu \mathrm{m})$ of each sample. Ice-rafted material can be of any size, but the size of grains deposited by bottom currents is limited by the velocity of those currents. A relatively fine fraction was therefore used in this study, to capture a greater proportion of the material transported and deposited by bottom currents than would be found in a coarser fraction.

Quartz grains were used for several reasons. It has been demonstrated that provenance information can be deduced from the shapes and surface features of quartz grains (Porter, 1962; Krinsley and Donahue, 1968; Krinsley and Doornkamp, 1973; Margolis and Krinsley, 1974; Ehrlich and Chin, 1980; Hudson and Ehrlich, 1980). In addition, quartz is nearly ubiquitous in sediments (including those of the

\footnotetext{
${ }^{1}$ Ruddiman, W. F., Kidd, R. B., Thomas, E., et al., Init. Repts. DSDP, 94: Washington (U.S. Govt. Printing Office)

2 Address: Department of Geology, University of South Carolina, Columbia, SC 29208.
}

deep sea), and generally resists change of shape resulting from transport. Quartz is also easily distinguished from other detrital minerals, owing to its lack of cleavage, its translucent nature, and its relief and lack of color. Quartz may be confused with feldspar, which, in the sediments studied, accounts for $<1$ to $1 \%$ of the detrital mineral component.

For each of the 38 samples studied, 400 quartz grains were digitized using the ARTHUR II digitizing system (Fico, 1980: Fig. 1). This system employs a video camera attached to a microscope, which projects the image of each grain onto a black-and-white TV monitor. The outline of the grain is then digitized and the coordinates are stored on a floppy disk. Each outline is then expressed as a closed-form Fourier series (Ehrlich and Full, 1984; Ehrlich et at., 1980, Ehrlich and Weinburg, 1970) with a harmonic amplitude and phase angle for harmonics 2 through 24. Each harmonic amplitude measures the contribution of a fixed harmonic shape to the total shape of the grain (Fig. 2A). In this series, the second harmonic is a two-lobed figure measuring elongation, the third is a trefoil which measures triangularity, the fourth is a four-lobed figure measuring quadrateness, and so on, to the 24th harmonic, which is a 24-lobed figure measuring surface irregularities (Fig. 2B). The Fourier-series data for each grain in every sample are then reduced using principal factor analysis (EXTENDED CABFAC, Klovan and Meisch, 1976). Output from EXTENDED CABFAC indicates how much information in the original data is retained after successive reductions in dimensionality. In other words, CABFAC is used to determine the number of end-members (or grain shapes) necessary to describe the data set adequately. From this algorithm we determined that a three-end-member solution best fitted the data. These end-members are described as a smooth grain shape or type, a second type is highly irregular, and a third which is intermediate in shape. After we determined statistically that there are three major grain shapes or types, the data were "unmixed" using a QMODEL unmixing algorithm (Full et al., 1982; Full et al., 1981; Klovan and Meisch, 1976). This algorithm gives the proportion of each end-member or grain shape in each sample. Using this information, we can select samples rich in the different end-members, examine them in a scanning electron microscope (SEM), and determine the surface characteristics of each grain type. These characteristics are then used to suggest a provenance for each grain type. All samples examined on the SEM were mounted with double-stick tape on aluminum stubs and gold-coated.

\section{RESULTS}

Analysis using the SEM indicated that each of the three grain types (smooth, intermediate, and irregular) 


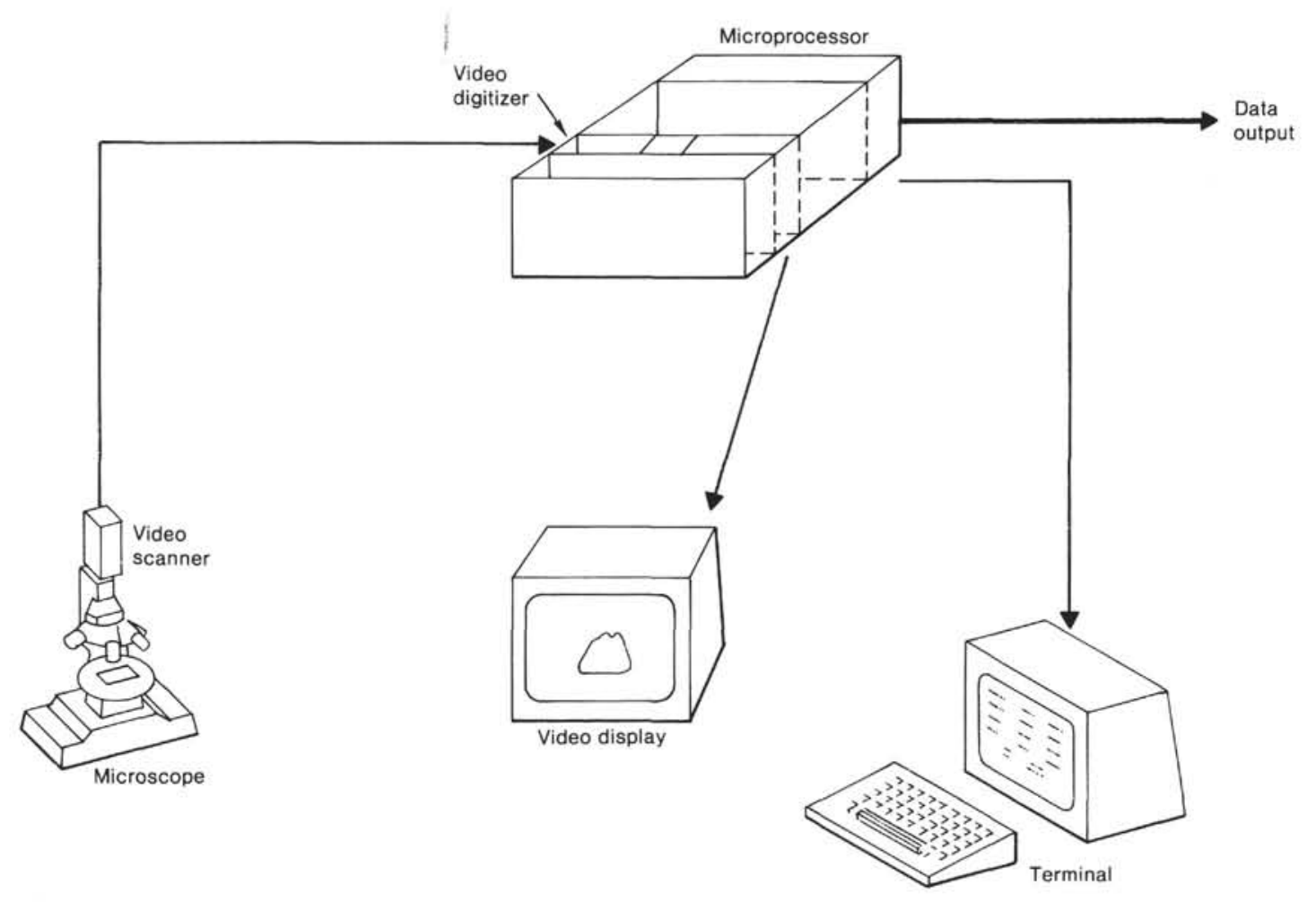

Figure 1. The ARTHUR II digitizing system (Fico, 1980).

has distinct features (Plate 1). Grains considered to be of the smooth type (Plate 1, Figs. 1-3) are rounded and covered with silica plastering. The intermediate type (Plate 1, Figs. 4-6) comprises grains with sharp, relatively unaltered, fractured surfaces. A third type (irregular) is highly irregular in overall shape and surface detail (Plate 1, Figs. 7-9), owing to the presence of delicate, unevenly shaped plates of silica. The three grain types represent three different origins. Each end-member (grain type) probably includes subfamilies of grain types carrying additional provenance information, which can be resolved only by further analysis.

Designation of the genetic environments of the first two grain types is relatively straightforward. Smooth grains (Plate 1, Figs. 1-3) were derived from igneous or metamorphic bedrock decomposed by soil-forming processes. Consequently, these grains display bulges and hollows which reflect the relationship between the quartz and its neighboring mineral grains in the source rock (Krinsley and Doornkamp, 1973). Some grains show signs of abrasion, such a V-shaped pits, but most have relatively abrasion-free surfaces. Intermediate grains (Plate 1, Figs 4-6) consist of quartz grains with conchoidally fractured surfaces and straight and arcuate stepped fracture patterns typical of grains from a glacial environment (Krinsley and Doornkamp, 1973; Margolis and Krinsley, 1974; Whalley and Krinsley, 1974). These grains were probably contributed to the sediment by rafted ice or by secondary distribution of ice-rafted material by currents.

The third grain type (irregular) is unusual in that it consists of quartz covered with delicate, irregular silica plates (Plate 1, Figs. 7-9). This typically gives the grain a spongy appearance under the SEM. An energy-disper- sion X-ray analysis (EDAX) system mounted on the SEM was used to substantiate that these irregular plates are indeed silica. Such irregular overgrowths indicate an interference of normal overgrowth development by finegrained material and by factors such as the absence of large fluid-filled pores adjacent to the grain. The delicacy of these overgrowths and the absence of abrasion features rule out long-distance transport of these grains from the continents into the deep sea after emplacement of this diagenetic surface texture. In our opinion, these grains are derived from diagenetically altered, fine-grained deep-sea sediments. Similar grains from sediments of the Hatteras abyssal plain have been described by Prince, (1984). It is unlikely that this diagenesis occurred in the sediment from which these samples were collected, since the intermediate grains are usually accompanied by large numbers of the other two grain types, which do not exhibit such overgrowths. Therefore, the occurrence of such grains in these sediments is evidence of submarine erosion, transport, and redeposition.

\section{Relationship Between Quartz Types and Glacial/Interglacial Intervals}

Initial classification of glacial and interglacial intervals was made on the basis of megascopic sedimentological criteria. That is, light-colored calcareous oozes were deemed "interglacial" and dark, muddy intervals, often containing dropstones, were classified as deposited during "glacial" intervals. This interpretation is supported by the presence of a "cold" planktonic foraminiferal fauna in dark sediments and of "warm" species in light sediments (Weaver, this volume; Raymo et al., this volume), and by similar nannofossil (Takayama and Sato, 
A
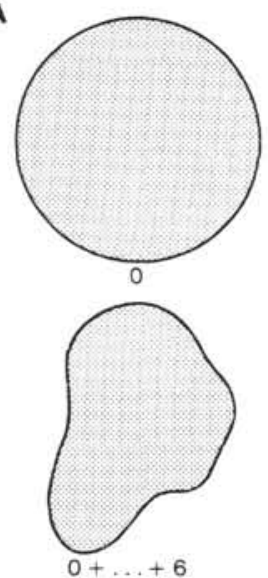

B
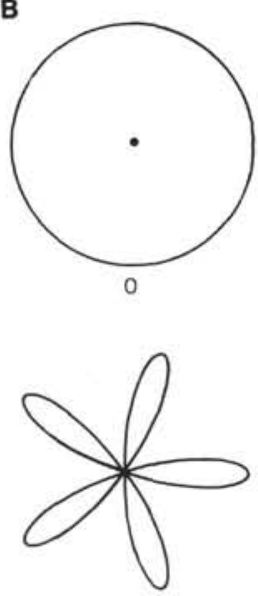

5
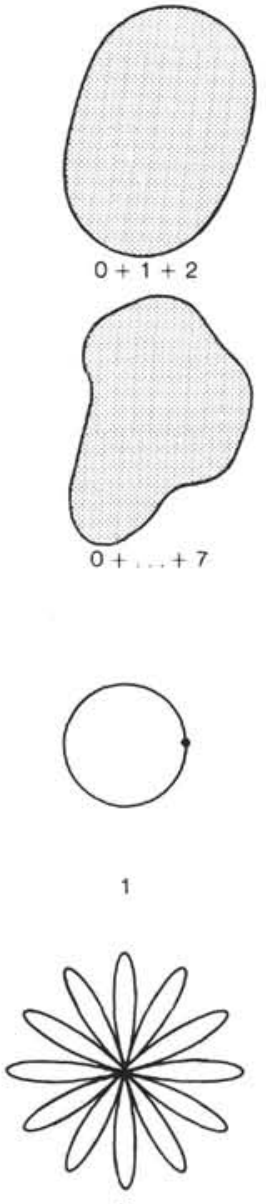

6
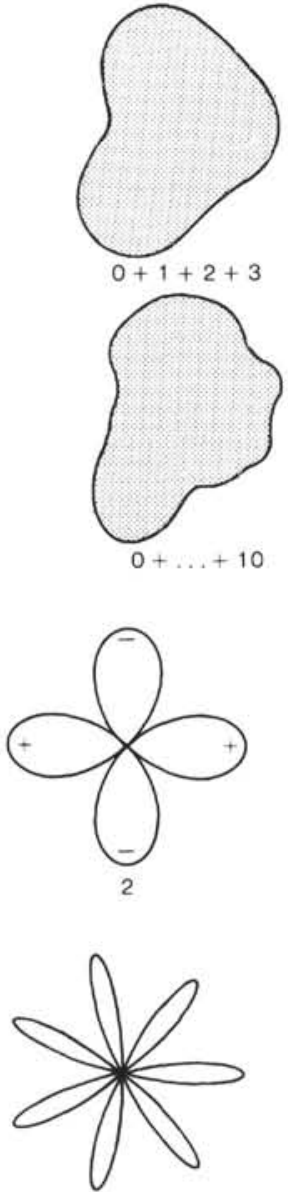

7
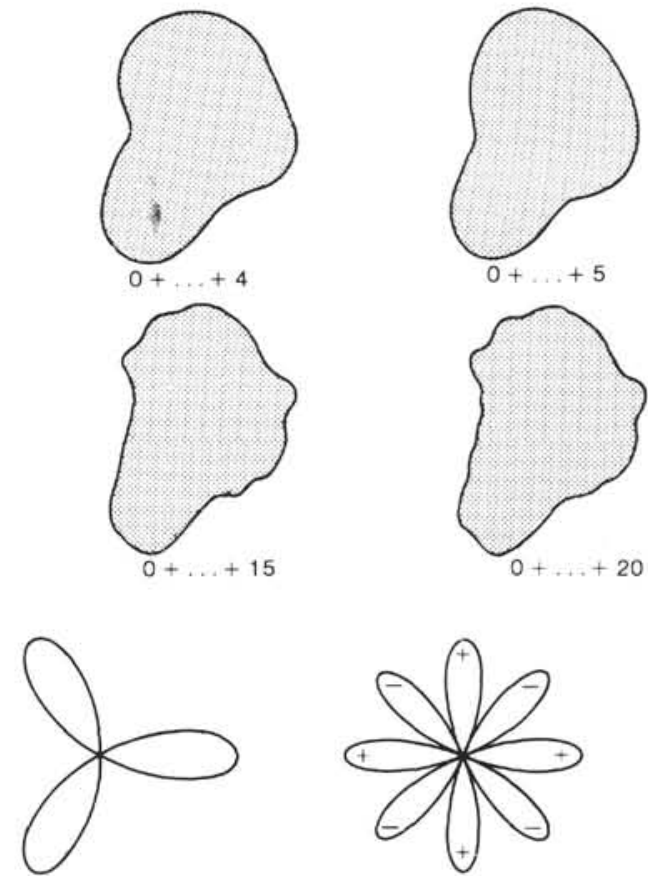

3
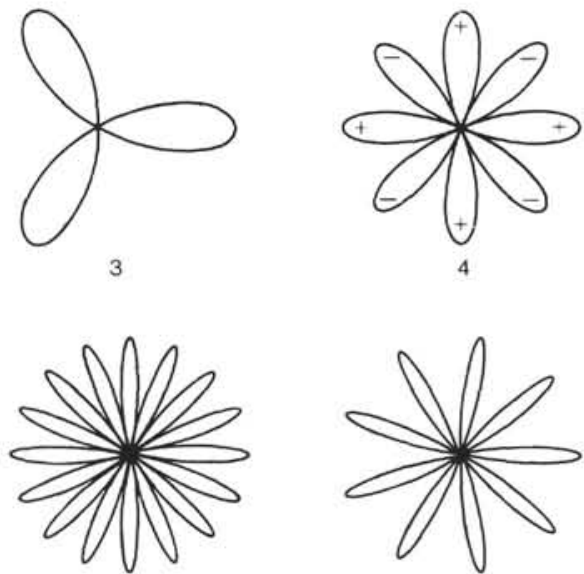

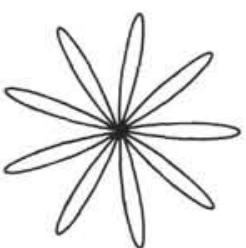

9
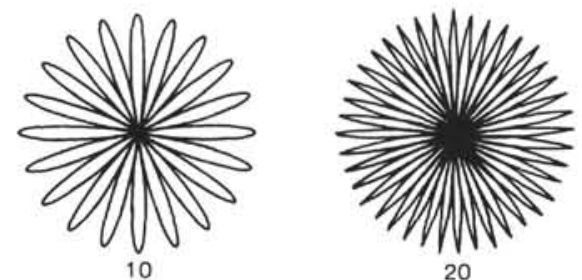

Figure 2. A. Reconstruction of original grain shape by the addition of successive harmonic contributions. Numbers indicate the harmonics contributing to each shape. B. Harmonic shapes used in the closed-form Fourier series. Amplitude = 1.00; phase angle $=1.00$.

this volume) and isotopic evidence (Ruddiman et al., this volume). A detailed study of Hole 552A (Zimmerman et. at., 1984), situated close to Site 610 , used isotopic, sedimentologic, paleontologic, and other data to show that light- and dark-colored sediments corresponded to warm and cold conditions, respectively. These glacial/ interglacial designations are not exactly equivalent to isotopic stages, but may instead represent smaller climatic oscillations within the various isotopic stages, as suggested by oxygen-isotope and corresponding color-index data given by Zimmerman et al. (1984).

To determine whether a relationship exists between climatic conditions and provenance, a set of eight paired samples from above and below glacial/interglacial contacts was selected from the top portion of Hole 611A (Cores 1-6) in the Gardar Drift. Results from the study of these samples are shown in Figure 3. These data illustrate that during the transition from interglacial (lightcolored units) to glacial (dark-colored units) intervals the percentage of smooth grains increases and the percentage of intermediate grains decreases (Fig. 3, open arrows), whereas the percentage of irregular grains varies little. When the transition is from glacial to interglacial, these trends are reversed (Fig. 3, dark arrows). The change in percentage is small but remarkably consistent.

To determine whether changes in the proportions of the different grain types occur systematically within an interval, several intervals were sampled from Hole 610A (Cores 1-3) in the Feni Drift. Results of these analyses are shown on Figure 4. Intervals $A$ and $D$ are glacial and $\mathrm{C}$ and $\mathrm{E}$ are interglacial. Interval $\mathrm{B}$ is labeled as "transitional," but in fact is made up of smaller subintervals 


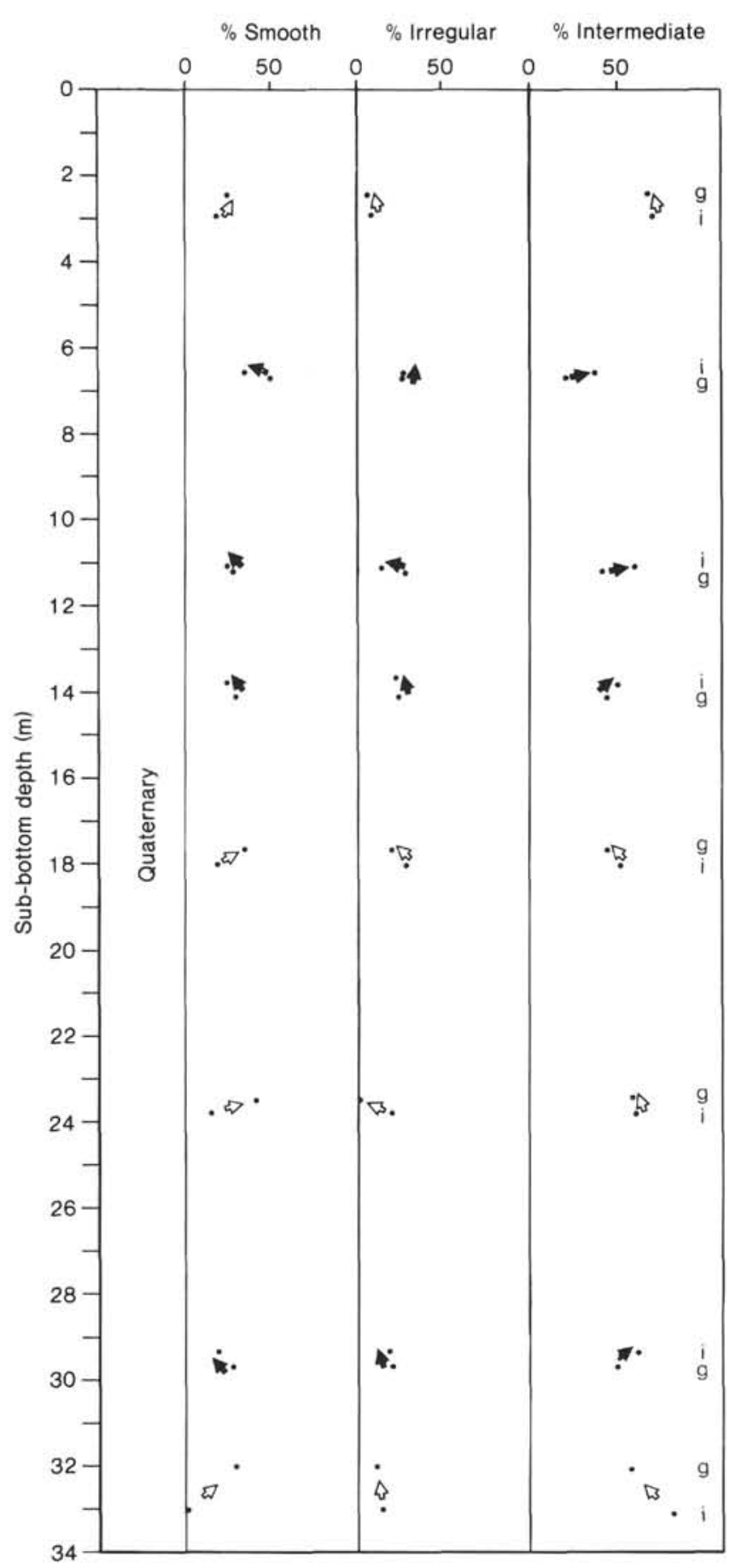

Figure 3. Paired samples taken above and below glacial (g)/interglacial (i) contacts in the upper Quaternary of the Gardar Drift (Hole 611A). Open arrows indicate interglacial-to-glacial transitions; darkened arrows indicate the reverse. Proportions shown are percentages of quartz grains of each grain type in a sample. Smooth grains are thought to represent continental material, intermediate grains represent ice-rafted debris, and irregular grains are probably derived from erosion of submarine outcrops. Note the consistent direction of variation in percentage of each grain type from glacial to interglacial and visa versa. which vary widely in degree of lightness or darkness. These may represent shorter and/or less intense climatic oscillations.

One of the most notable differences between the glacial and interglacial intervals is in the variability of the proportions of the three grain types. In glacial intervals (Fig. 4, A and D), the proportion of each grain type varies widely. In addition, these proportions tend to reach a maximum or minimum near the middle of the glacial intervals. Within interglacial intervals (C and $\mathrm{E}$ ), however, there is little variation in the percentages of each grain type. In interval B, suggested to be transitional, the smooth and intermediate grain types vary greatly and inversely. The irregular grain type varies little except in glacial intervals.

The most direct explanation for the abundant smooth grain type is transport by ice without alteration of surface textures that had previously been imparted during a phase of fluvial transport. Several mechanisms are possible: (1) sediment loads carried out onto fast sea ice at river mouths during early spring thaws; (2) river-derived grains frozen into basal layers of sea ice along shallow continental margins; and (3) quartz grains incorporated

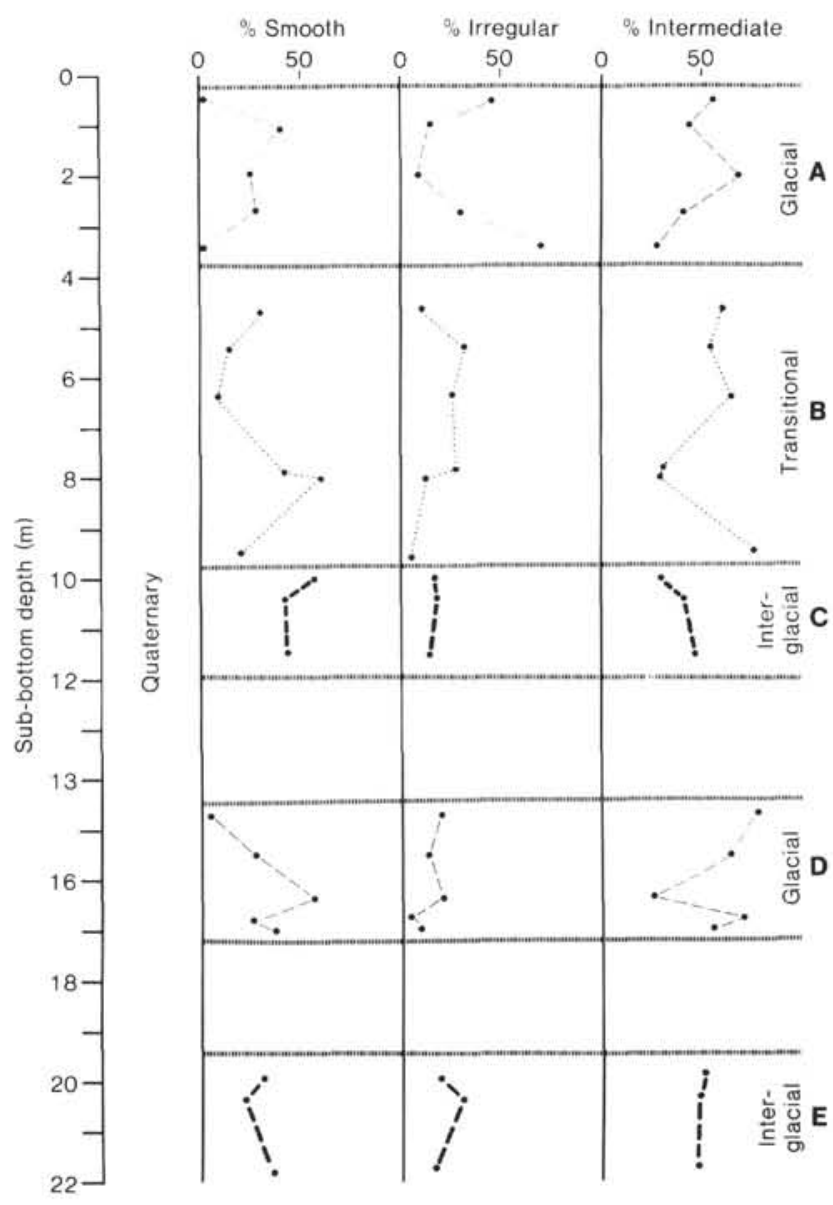

Figure 4. Samples taken within glacial and interglacial cycles in the upper Quaternary of the Feni Drift (Hole 610). Note the large variation in percentage of each grain type within glacial cycles. The variation decreases greatly within interglacial cycles. Intervals A-E are discussed in text. 
into glacial ice sheets without alteration and subsequently carried to the ocean by icebergs.

Alternatively, the increase in abundance of smooth grains at the beginning of a glacial interval may be due to the initial exposure and shallowing of the continental shelves. As sea level falls, material previously trapped on the shelf and upper slope is flushed out onto the abyssal plain, increasing the availability of continental material to the deep sea. This material probably dilutes the initial contribution of ice-rafted material at the beginning of a glacial interval. When the sea level subsequently rises, the area that provides this shelf-derived material again becomes more restricted, and a smaller area is available to serve as a sediment source.

\section{CONCLUSIONS AND IMPLICATIONS}

Three grain types have been identified within the very fine quartz sands of the Feni and Gardar drifts: smooth, derived from continental bedrock; intermediate, transported by ice-rafting; and irregular, redeposited by currents. Systematic changes occur in the relative importance of each grain type, both during the transition from glacial to interglacial intervals and within intervals. Such changes are possibly due to the (1) increased availability of continentally derived material (smooth) at times of lowered sea level, (2) increased amounts of sea-ice (intermediate), and (3) changes in path and velocity of bottomcurrents which erode and redeposit material from the ocean bottom and/or submarine outcrops (irregular). The percentage of each provenance type varies little during interglacial intervals but varies widely during glacial intervals. This suggests that factors affecting provenance are subject to greater change during glacial intervals.

Since a minimum of $15 \%$ of the very fine quartz sand consists of identifiable, reworked grains, it is likely that at least that much of the silt- and clay-sized fractions is also reworked, since finer fractions could be transported even more easily. Some reworked material may not be easily identified, however, and initial estimates of the percentage of reworked material in the drifts may be too low. The presence of substantial amounts of reworked material suggests that the rate of drift accumulation is not directly dependent on a contemporaneous input from continental masses. Estimates of rates of continental erosion through time, based on deep-sea sedimentation rates, should therefore be regarded with caution.

This initial work shows that the detrital quartz component in the fine fraction of the Feni and Gardar drifts contains at least three provenance signals. These include material derived directly from the continents and material deposited after rafting by ice. A third provenance is the seafloor itself. The presence of identifiable grains which have been eroded from, and redeposited on, the seafloor indicated that bottom currents may indeed play an active role in drift sediment accumulation, despite the apparent lack of current structures in sediment cores. It is also evident that variations in climate have a defi- nite effect on the amount of material contributed by each source area. However, present data are insufficient to define clearly the exact relationship between climate change and provenance of the fine-grained detrital quartz. Further work involving more detailed sampling of various glacial and interglacial sequences should provide greater understanding of sediment accumulation during various climatic conditions.

\section{ACKNOWLEDGMENTS}

The authors are grateful to Ellen Thomas and Bill Ruddiman for their help in the revising of this manuscript. Thanks also to Steve Kennedy and J. P. Syvitski for their helpful reviews of this paper.

\section{REFERENCES}

Ehrlich, R., Brown, P. J., Yarus, J. M., and Przygocki, R. S., 1980. The origin of shape frequency distributions and the relationship between size and shape. Sediment. Petrol., 50:475-484.

Ehrlich, R., and Chin, M., 1980. Fourier grain-shape analysis: A new tool for sourcing and tracking abyssal silts. Mar. Geo., 38:219-231.

Ehrlich, R., and Full, W. E., 1984. Fourier shape analysis-a multivariate pattern recognition approach. In Beddow, J. K. (Ed.), Particle Characterization in Technology (Vol. 2): Boca Raton (CRC Press, Inc.), 89-101.

Ehrlich, R., and Weinburg, B., 1970. An exact method for characterization of grain shape., J. Sediment. Petrol., 40:0205-0212.

Fico, C., 1980. Automated particle shape analysis: Development of a microprocessor controlled image analysis system [Master thesis]. University of South Carolina, Columbia, SC.

Full, W. E., Ehrlich, R., and Bezdek, J. C., 1982. FUZZY QMODEL: A new approach for linear unmixing. Math. Geol., 14:257-268.

Full, W. E., Ehrlich, R., and Klovan, J. E., 1981. EXTENDED QMODEL-Objective definition of external end members in the analysis of compositional data. Comput. Geosci., 7:331-344.

Hudson, C. B., and Ehrlich, R., 1980. Determination of relative provenance contributions in samples of quartz and using Q-mode factor analysis of Fourier grain shape data. J. Sediment. Petrol., 50: 1101-1110.

Klovan, J. E., and Miesch, A. T., 1976. EXTENDED CABFAC and QMODEL computer programs for Q-mode factor analysis of compositional data. Comput. Geosci., 1:161-178.

Krinsley, D. H., and Donahue, J., 1968. Environmental interpretation of sand grain surface textures by electron microscope. Geol. Soc. Am. Bull., 79:743-748.

Krinsley, D. H., and Doornkamp, J. C., 1973. Atlas of Quartz Sand Surface Textures: London (Cambridge University Press).

Margolis, S. V., and Krinsley, D. H., 1974. Processes of formation and environmental occurrence of micro-features on detrital quartz grains. Am. J. Sci., 274:449-464.

Porter, J. J., 1962. Electron microscopy of sand surface textures. $J$. Sediment. Petrol., 32:124-135.

Prince, C. M., 1984. Provenance and dispersal patterns of late Pleistocene-early Holocene sediment in the Hatteras abyssal plain [Masters thesis]. University of South Carolina, Columbia.

Whalley, W. B., and Krinsley, D. H., 1974. A scanning electron microscope study of surface textures of quartz grains from glacial environments. Sedimenthodology, 21:87-105.

Zimmerman, H. B., Shackelton, N. J., Backman, J., Kent, D. V., Baldauf, J. G., Kaltenback, A. J., and Morton, A. C., 1984. History of Plio-Pleistocene climate in the northeastern Atlantic, Deep Sea Drilling Project Hole 552A. In Roberts, D. G., Schnitker, D., et al., Init. Repts. DSDP, 81: Washington (U.S. Govt. Printing Office), 861-875.

Date of Initial Receipt: 11 February 1985 Date of Acceptance: 17 September 1985 

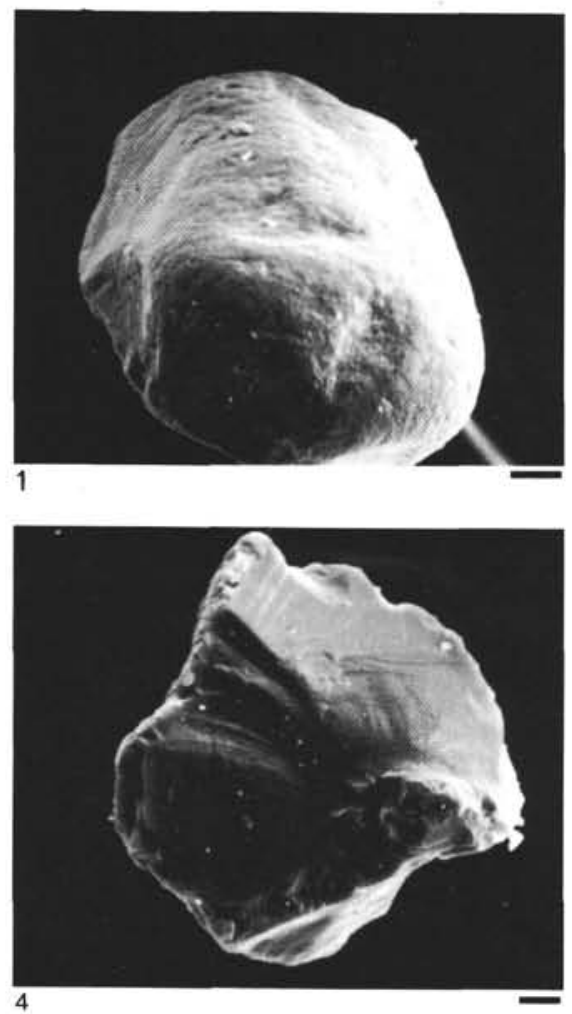

4

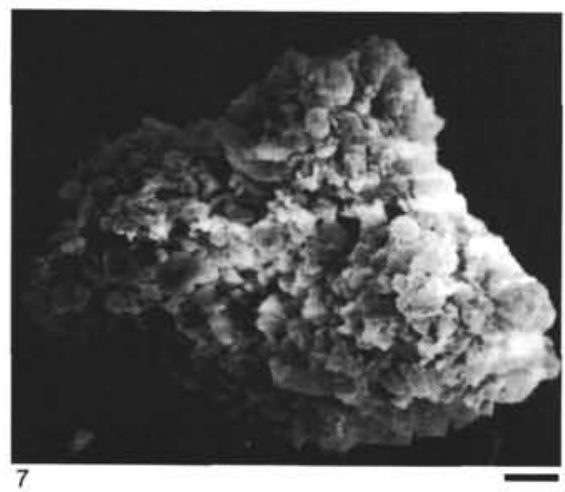

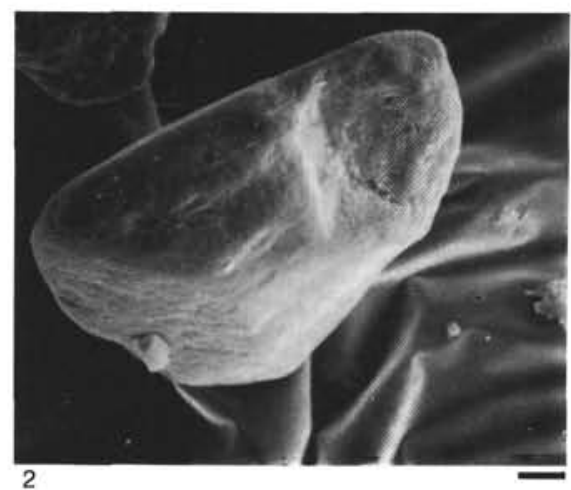
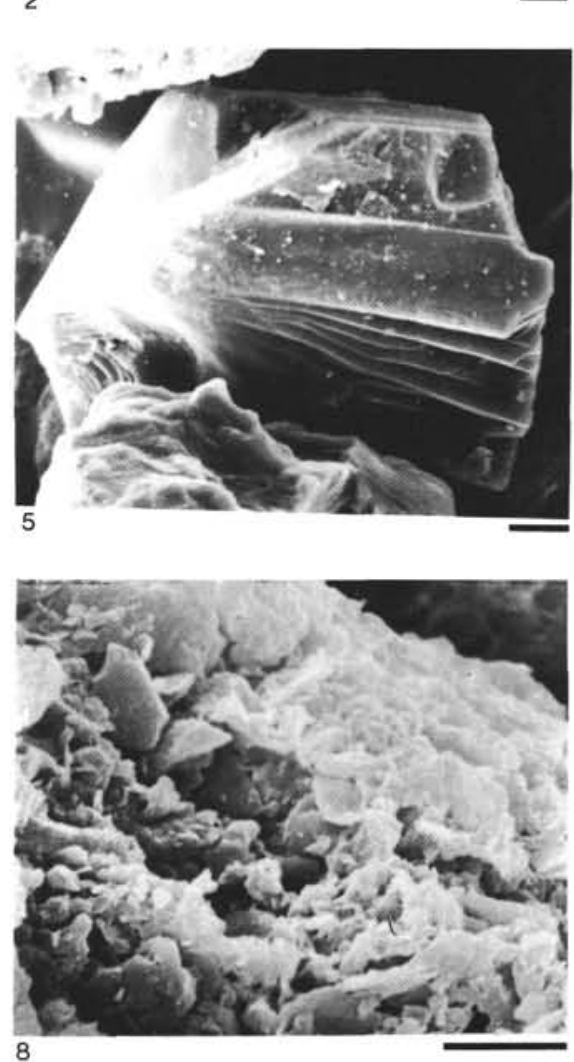
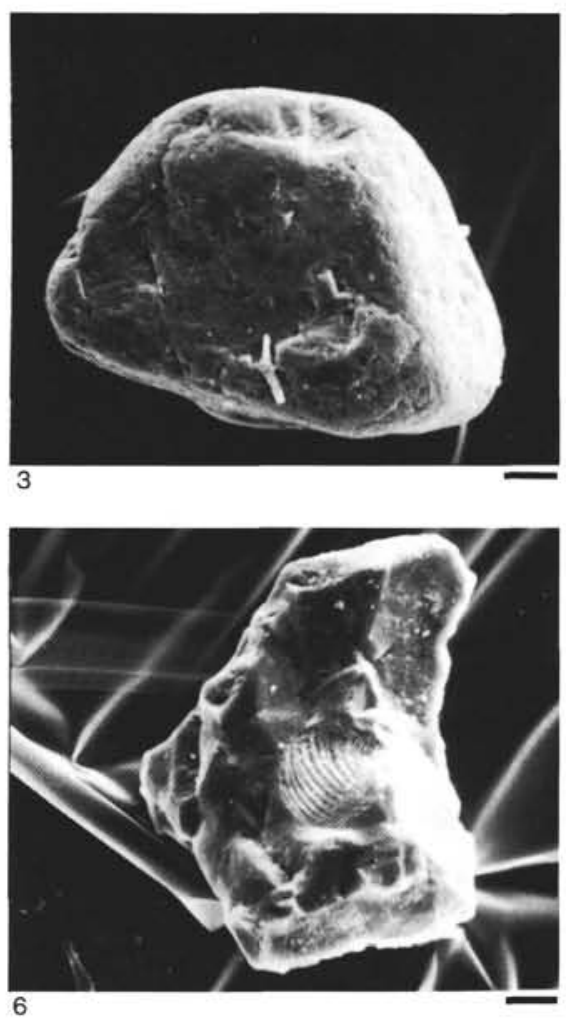

6

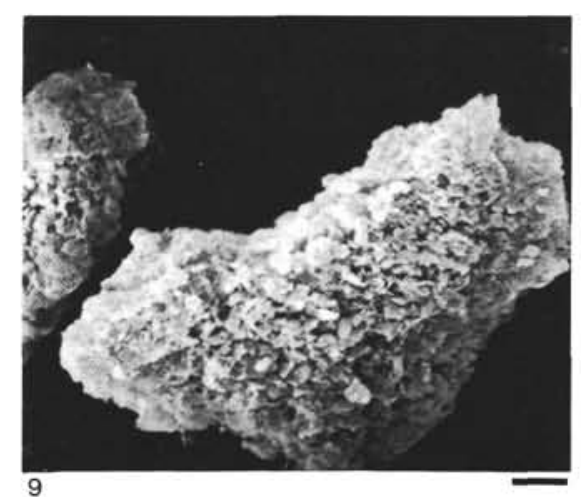

Plate 1. Photomicrographs of quartz grains from the very fine sand $(63-90 \mu \mathrm{m})$ fraction of samples from the Feni and Gardar drifts (bar $=$ $10 \mu \mathrm{m})$. 1-3. Smooth grain type. These grains are generally rounded and are covered with fine-grained silica plastering. 4-6. Intermediate grain type. These grains are covered with relatively fresh, typically conchoidal fractures. 7-9. Irregular grain type. These grains are covered with delicate, irregularly shaped plates of silica (8) and are thought to represent erosion and redeposition by bottom currents of fine-grained (lutitic) sediments. 